\title{
PERCEPTION OF THE SPIRITUAL SYMBOL IN ARMENIAN MEDIEVAL PHILOSOPHY AND THEOLOGY
}

\begin{abstract}
The article presents the perceptions and viewpoints of the Armenian medieval literary men concerning the spiritual symbol. Being anchored in the pan-Christian perception of the symbol, it laid the basis of the symbolic-allegorical thinking of the Armenian spiritual culture.

In the history of the Armenian medieval literature and art studies, the analysis of symbols, in essence, the discovery of the epiphany in them, which is the fundamental meaning of the culture, have often been neglected.

Today there is a necessity to analyse the spiritual culture in a new way to dig out its ideological world outlook basis conditioned by the artistic and the festival and ritual functions of the different types of art. Such a research also enables us to comprehend the aesthetic, artistic and doctrinal - philosophical merits of the spiritual culture (literature, miniature, architecture, etc.) created throughout the centuries and still unknown to us in a new way, to review the system of criteria and ideological-methodological basis of the evaluation, which bears a great significance for the complete and precise perception and evaluation of the Armenian art and literature of the Middle Ages (see Alvrtsyan, 2017).

Keywords: spiritual symbol, allegory, the Middle Ages, philosophy, Christianity, the Bible.

The knowledge of God is possible only due to appearing manifestations of the ineffable God, which is applied in the literature and in the art in general by the allegorical thinking. The timber of this thinking is the symbol. This phenomenon is older, so old as the religious perception of the world since as rightfully has noted S. Averintsev (1977) “...every religious, and mystic consciousness by its nature is compelled to create for itself a system of sacred signs and symbols without which he would not be able to describe its "ineffable" content" (pp. 123-124).

The expression of the content of religious consciousness as a world outlook entirety, as a comprehensive system of values, finds its reflec-

tion not only in the ritual and lifestyle works that are considered primary, but also in the theological, philosophical, literary, and cultural works considered the ideological, world outlook and theoretical basis for them.

In the Christian doctrine, the symbolic-allegorical perception of the world is anchored in the unshakable faith that this material world is merely the reflection of the other world- its symbol. If the material world is comprehensible to many, then as Nerses the Graceful is convinced a few are able to comprehend and perceive the genuine sacrament, "...the symbol is known not to everyone, but a few and only the Absolute God" (Ghazaryan, 2004, p. 275).
\end{abstract}


Since the $1^{\text {st }}$ century for the Christian literature (theology, commentary, speech writing, fiction works) the symbolic-allegorical style for the narration of the Bible becomes a universal reality, the essence of which has been a stone of stumbling for the incompetent practical-materialist thinking at all times.

In the Middle Ages it is the commentary works that greatly contributed to the tantamount perception of both the Bible and the cultural and fiction works, the authors of which were not only the fathers of the church and famous theologists but often the poets, as there were Stepanos Syunetsi, Gregory Narekatsi, Nerses the Graceful, Gregory Tatevatsi and others among us.

The presence of the 'sacred mystery' of the Bible and the spiritual culture in the history of literature has been realised at the present time too. While speaking about the Bible Commentaries of the $1^{\text {st }}$ century, M. Abeghyan (1968) notes that Pilon Judaeus "... the allegorical explanation had employed on the Old Testament...Along with the allegorical commentary they employed also abstruse, recondite pieces of word explanation. Later, however, the allegorical commentary becomes very favourite..." (p. 96).

While touching upon this significant issue, Russian famous literary critic, renowned researcher and theorist of the medieval literature D. Likhachev states that the medieval literature and culture were imbued with an aspiration for the symbolic-allegorical commentary of the scripture of the history of nature. He sees the roots of this phenomenon in the Greek literature, "The late Greeks (Hellenistic period) were inclined to comment their mythology parabolically. Still, the apostles commented the Old and New Testaments parabolically, which being under the influence of the late Greek philosophy, gained great influence in Aleksandria, where it became a system in the Origen philosophy" (Likhachev, 1985, p. 175).

Although many have noticed the presence of the religious allegory in the Armenian spiritual poetry, starting from M. Abeghyan, yet this issue has been touched upon superficially, slightly. M. Abeghyan (1968), considering the cantos by Gregory Narekatsi the apotheosis of awakening of the nature and love (even if 'incorporeal'), yet he notices that "The nature, the spring of Narek, as for the medieval and not only for the Armenian church singers, but in general, is an allegory, a symbol merely for the Nativity of Jesus" (p. 595).

Despite this rightful observations, in the history of the Armenian literature, almost always the subjective (literal) method of the perception of the allegory prevailed, while as V. Bichkov (1981) has rightfully noticed, "The complicated, rich and deeply unique medieval culture, just as the Eastern Christian, and also the Western, cannot be comprehended and perceived without considering the early Christian and the early medieval apprehensions of the image, the symbol, the sign, the allegory" (p. 290).

According to Nerses the Graceful, the main prerequisite for the perception of the symbol in the medieval spiritual cultures to discover the invisible, the untouchable, the abstract (sacrament) "merely known to the God and a few" (Ghazaryan, 2004, p. 275), to make it communicable and comprehensible because the visible side of the creation (the subjective world- secondary) is only a method for its invisible side (divine - essential) for the cognition and for becoming competent and be in communication with it. The ideological basis and the essence of the medieval literature and the culture, in general, are the ineffable point of the Bible, according to which on the Earth and in the Heaven eve- 
rything and everyone is to recognise the God and are created for that purpose. As Paul, the Apostle writes the visible things are just methods to explain the invisible ones, "His invisible features, i.e. his eternal potency and divinity are clearly seen since the creation of the world, for they are seen through the created things" (Rom 1:20, King James Version).

This idea, which should have been pivotal for the theologists and for different theological and philosophic (especially Neoplatonic) directions that pursue the main issue of recognizing God, became a landmark in the Armenian philosophical and theological thought already in the $5^{\text {th }}$ century. Famous medieval Armenian philosopher David the Invincible divided the cognisable beings into exactly existing beings, which are recognizable at the perceptive level: these are the visible, the tangible beings - the whole material world, and the beings that are recognizable by the mind, and such is God. To his conviction, the origin and the reason for the cognizable beings is their creator - God- who is also the apogee of everything. One may approach to God only by following his creations and their motions, recognising them by mind and outlook. He believes that the opportunity to reach the ineffable God directly follows from this idea, "And we speak about the theology that even though the divine is by itself unrecognisable but by looking at his creations and creatures as well as at the regulated movement of the world, we will reach the creator by the thinking and by the outlook. The invisible easily becomes cognisable through the visible" (David the Invincible, 1980, p. 35).

However, the visible, materialistic world, by itself, does not give an opportunity for cognition: the words naming the subjects of that world are just conditional signs that are indicators of a type and gender in the diversity of the materialis- tic world and play a role of a conditional sign for the mental cognition of the materialistic world. But then from the starting point of the idea of Paul the Apostle those conditional signs turn into symbols since they are not independent, but they are created for the cognition of the God, thus they have sacred element, "The symbol differs from a conditional sign by the presence of its sacred element with a certain similarity with plans in the expression and the content" (Avernitsev, 1977, p. 249).

The realisation of this similarity was clearly shaped in the Armenian theological and philosophical thought of the $5^{\text {th }}$ century. Yeghishe (1859) realises this issue very accurately by speaking about the appearance of God to the prophets in different images and none of them could see God, but they saw him only by the similarity and they got satisfied by that (p. 227).

The cognition occurs through the symbolicallegorical perception streamed from the contradiction of the visible world and its invisible essence. By thoroughly analysing this principal question, H. Kyoseyan (1995) concludes, "Thus, the "sacrament" and the "similarity" (symbol) are not the identical manifestation of the "truth" and the "essence". Namely, when the "truth" or the "essence" is displayed, it becomes "sacrament" or "similarity", which, by bearing the imprint of its exemplar, however, differs from it by its nature. Such perception of the symbol is based on the denialistic (apophatic) theology adopted by the Armenian church, according to which God or the Essence principally is unrecognisable or unreachable, and the communication with him occurs through the sacraments illustrating the divine truth and the symbols" (p. 85).

Significantly interesting are the ideas of famous chronicler and theologist of the $8^{\text {th }}$ century 
Hovhannes Odznetsi about the symbol. Above we spoke about the sacrament and the similarity, on the occasion of Odznetsi, we would love to touch upon homologous another principle question, which was a subject of a long-lasting debate among the theorists of iconoclasm: that is a matter of the character and its depiction. Odznetsi (1953) explains this not in a figurative way: we worship not the material of the Cross but merely the sign of the Cross as "a victory sign and image of the God's single Son" (p. 47). If we do not take into consideration the symbolicallegorical nature of the image, then we will fall into materialism as the idolaters, who worship the material, since, as Odznetsi explains, "we depict living and life-giving Jesus in anthropoid physical" (p. 52). Namely, the material itself has neither value nor power. We gain divine power not from the ritual subjects or from the hand making the ritual but from the Holy Trinity (p. 56).

In the question of interpretation of a symbol and making it meaningful, it is worth mentioning also a great connoisseur and theorist of a symbol, and symbolic-allegorical speech, the founder of the interpretation of khoran (canon-table) Stepanos Syunetsi. At the beginning of his commentary he notes that it is the beauty of the divine speech that is more astonishing, which the evangelists expressed in sublime words that are presented in 10 khorans (canon-tables): he explains, "in proper, harmonious words one by one twining according to the (Bible) recital that purports about Jesus" (Ghazaryan, 2004, p. 255). We need to add that the role of Syunetsi was great not only in the commentary of the symbols but also in the allegorical interpretation of the spiritual speech. From this point of view, his interpretative work "The Commentary of Four Evangelists" was of great contribution.
In the theory of the spiritual symbol, and especially in its interpretation, notably significant is the role of Gregory Narekatsi, who virtually is the first theorist and coordinator of the Armenian spiritual poetic symbol. In the commentary of the "Song of Songs" like Gregory Syunetsi he follows Paul the Apostle by commentating the sacraments of "physical subjects" since all the subjects have sacrament concealed from a man. To his conviction, King Solomon tells ineffable things in the "Song of Songs" by likening to the corporeal - bride, gloom, nephew and maiden, daughter and breasts, dove, Jerusalem, gardens and other appealing things, because the valuable (symbolic) things should always be concealed since the appearance is always much attractive that the inside hidden treasure (Narekatsi, 1840, p. 273). For the characterisation of the symbol, he ends this principal thought with a figurative comparison, "As the parents of children hide the valuable things in a nice pot because the appearance is more preferable to them than inside hidden treasure in order to exhort them to maintain carefully what is hidden inside, in the same way, the sweet and precious oil - spikenard- as he says, it is kept in the pot because the sweet smell cannot be left in the open air, as the Lord says in the Holy Bible not to give the ineffable things to those, who are unable to comprehend" (Narekatsi, 1840, p. 273).

Here the confidential nature of the symbol has a principle significance: virtually the sacrament is comprehensible to a few not because it is disguised with the mysteriousness of secret ritual, but because the ineffable - the word of Godis not for "those with weak hearing", but only for those who strive to reach the sacrament, which is the main essence of the allegorical narrative of the Holy Bible, on the symbolic-allegorical basis of which the symbol of the Christian culture was 
formed.

Gregory Narekatsi, who is virtually the first theorist and coordinator of the symbol of the Armenian spiritual poem, in the commentary of the "Song of Songs", following Gregory Syunetsi and the main principle of the Bible in general, interprets the meanings of the "corporeal things", for all the things have meaning concealed from a man.

Approximately two centuries after Gregory Narekatsi that was Nerses the Graceful who mentioned about the significance of the "concealed" word and its perception:

"Some are to be given talent,

Others should be given a meaning of the

concealed speech..." (Nerses the Graceful, 1830, p. 164).

Moreover, in the commentary of the khorans (canon-tables) of the Gospels, Nerses the Graceful interprets in detail the "hidden" meanings of the symbols (words, colours, birds, animals, images, numbers, etc.) and the spiritual sacraments (Ghazaryan, 2004, pp. 266-299), as Gregory Narekatsi does with the symbols of the "Song of Songs". Though, with the word "hidden" the two great poets directly hint the allegorical content expressed in symbols.

In the Armenian philosophy, the concept of the symbolic- allegorical perception of the world was prevalent throughout the Middle Ages. Moreover, it is not only the world of this side is a symbol for understanding the world of the other side, but also according to a famous philosopher of the 13th century Vahram Rabuni, if the God is also to some extent comprehensible to us, it is because of the fact that he appears in the form of subjects in different images (a child, an old man, a priest, a soldier, etc.) ("Confession of Vahram Rabuni", p.168) who "are not the images the God but the expression of his will and grace, ap- peared to the men in the images of symbols" (Ghulikyan, 2011, p. 135).

In the Armenian philosophy of the Middle Ages, the symbol has a significant role in understanding the meaning of creation and for its interpretation. According to 14 th- century philosopher Matthew Jughayestis "the universe is a set of symbols, which should be read and interpreted as the Bible" (Zaqaryan, 1997, p 9). He mostly concentrates on the meanings and symbols or subjects rather than on their substance and structure. From this point of view, his following thought is notable: since the sky is inaccessible it is natural that nothing can reach it "and make the inaccessible height of the God comprehensible because no thought can reach its divine height" ("Vetsorya (Six days)", p. 265a).

The philosophical views of Jughayetsi regarding the features of the four elements of the foundation of the material world - the soil, the water, the air and the fire - are also impressive. From his point of view, not only the elements but also their features symbolise a divine feature ("Vetsorya (Six days)", p. 265b).

Jughayetsi is sure that "the four elements composing the universe, the heavenly and the earthly bodies, plants and animals, inanimate things, the six types of movement being the materialistic basis of the creation are overloaded by semantic and epilogue lightening. They bear the traces of divine wisdom, symbolise different even confronting phenomena. The man reads that "book" and "learns different meaning from it" (Zaqaryan, 1997, p. 10).

In the mysterious-symbolic perception of the world, besides the recognition of the things and the meanings of their relationships, the numbers had a significant role. With his unique views about the numbers in the ancient world especially famous was Greek renowned mathematician 
and philosopher Pythagoras. He and his followers, the Pythagoreans, saw the number in the basis of the existence of the world and its harmony, and to their conviction, only by numbers, it could be possible to explain the essence of things. Moreover, the famous thought of Pythagoras that "God is an ineffable number" streams out from this philosophy. Later Plato, who was a Pythagorean, became famous for his views on numbers and brought the philosophy of a number at a new level. In the research about the philosophy of Pythagoras and Plato in the Narek school, Hr. Tamrazyan (2004) writes, “In Plato's works the emotional and ideological worlds differ from each other, which is the foundation-stone of his philosophy. As a result of it, as an indissoluble part of the ideal world, the number gets separated from the emotional world by becoming the idea of forming and embodying the emotional world" (p. 99).

In the ancient world and the Middle Ages philosophers, theologists and interpreters were sure that the number, the size and weight were based on the harmony and perfection of God's creation. Long before Pythagoras, this idea was in the Old Testament: we read in Solomon's "Wisdom", "But you did everything in size, number and weight". Nerses Lambronatsi, an Armenian interpreter of "Wisdom", thinks that "the size and weight are unreachable to us but everything is regulated and corrected by that" (Lambronatsi, 2004, p. 182).

In the $5^{\text {th }}$ century, the Armenian literary men were already well aware of the scriptural viewpoints about the number as well as about the philosophy of Pythagoras and Plato and the existing theories the number. Yeghishe was not only familiar with those teachings, but also profoundly realised the meanings of the symbols expressed in numbers and gave exciting com- mentaries. Apropos, it is noteworthy Yeghishe's commentary on number seven unique with its mysteriousness, polysemy and application: while speaking about Solomon's seven locks of hair, in which the secret of his mystic strength is hidden, he explains that number six in number seven symbolises the six days of creation and number seven symbolises God's seventh holy day. Then the interpretations of the number seven follow, which are quite a lot and exciting, but since our mission is to give an idea of the phenomenon, we will satisfy with this much (Yeghishe, 1859, pp. 190-191).

Noteworthy it is the views of the interpreters of the khorans (canon-tables) about the meanings of numbers. We read in the commentary by Stepanos Syunetsi, "And the horns of the arches there on the capitals, a pair of red and blue anchored beside each other and by five parts they mean the five judicial and the five boards of the Law" (Ghazaryan, 2004, p. 259). Namely, the two of the five parts of the capitals separately (with five - five parts) as numbers symbolise the two spiritual concepts.

Nerses the Graceful writes about the mysteriousness of the ninth khoran (canon-table), "Thus, the ninth khoran is symbolic- allegorical that three times three shows us the three concordance evangelists - Matthew, Mark, and Luke..." (Ghazaryan, 2004, pp. 287-288). The nine is the tripled three that symbolises the three concordance evangelists, and the meaning of the three is obvious: the third khoran's arches are three, “... as the personality of the Trinity is known to those who learnt the Holy Trinity from the Seraphs and taught the prophets" (Ghazaryan, 2004, p. 277).

With the commentaries of the meanings of numbers especially remarkable is Gregory Tatevatsi: in the interpretation of the "Theory of the 
List of the Bible." he focuses on the purports of the numbers by touching upon the meanings of all the khorans (canon-tables) in detail. From this point of view especially remarkable is the following excerpt, "Again change the order (of the numbers) since the four is close to us. And the three follows the one (and the number that comes) by the order. The one shows the natural law that was given to the ancestors, the two shows the natural law that followed the one, the three shows the written speech that followed the two, the four, in which there are four - the New (law) and the Gospels - followed the three". And as three times three is nine, it means the written speech is imperfect and it was given to the imperfects. And the four of the New Testament, from which the ten derives, is perfect and is given to the perfect. All again, the first four with the rest three means [the Gospel] of Matthew, the three with the two is for Mark, the two with the other one [evangelist] is for Luke, and the one is for John, and no one after him" (Ghazaryan, 2004, pp. 339-340).

The number four that symbolises the four Gospels is considered perfect given to the perfects since the number ten originates from it (the four is the only number that has both number one, and number two, and number three, and number four, the sum of which is ten).

In the commentary of one line of the "Song of Songs" (You poured our heart with yearning, or sister - in - law, with your one look, with a necklace of your neck you pored our heart with yearning! 4,9) Gregory Tatevatsi conveys us additional information about the perfection of the number four, "According to the body, the necklace is the golden string that the bride puts on her face or neck. Moreover, it is four because it is made of four materials - gold, silver, gems and pearls. Moreover, the necklace of the church is the sweet yoke of the Gospel, and the four is the faith, the hope, the love and the holiness or the repentance of the body, which Zacchaeus accepted, "I will repay fourfold" (comp. with Luke 19:1-8, King James Version), namely I will repent by my body made of four materials. And again, the repentance is four for one sin, namely regret, confession, repentance of body and pitifulness" (Tatevatsi, 2005, p. 57).

The allegory expressed in numbers was one of the most popular methods. The main reason of that is that the number has an opportunity to say a lot with few means, and what is more significant its "password" was not a big secret for an educated medieval man. P. Khachatryan rightfully noticed that "As natural and comprehensible they (i.e. the numbers) seem to an intellectual man of the Middle Ages, as strange and scholastic they seem to the thinking of modern days. Nevertheless, it is especially in this field that the interpreters help to dig out some hidden layers from the work by Gregory Narekatsi" (Khachatryan, 1996, p. 352). Though, as it was mentioned the symbols expressed in numbers were natural and comprehensible to an intellectual man of the Middle Ages, yet even to many of them was every allegory understandable and explainable: often some of them were left inexplicable and incomprehensible for centuries.

Even this brief review is enough in order to get an idea about the nature of the spiritual symbol expressed in numbers, which has a unique significance in the system of the medieval artistic thinking as a timber of allegorical speech.

The Armenian early Christian theoretical thought even in the 5th century clearly realised the spiritual symbol in general; however the different types of the art had to pass a way in order to form their symbol since, "...as in the history of the culture, any linguistic - philosophical system 
describing a significant object feels its inferiority, if it does not defines its symbol" (Lotman, 2000, p. 240).

Though each type of the art forms its system of a symbol, yet as separate manifestations of a unitary religious outlook and perception of the world, in terms of the content of symbols, they have similarities. Nevertheless, for ritualworshipping and literary-artistic functions, they have different roles and inclusions.

In the research dedicated to the theology of the Armenian church in psalms and taghs $\mathrm{H}$. Kyoseyan writes, "In the Armenian medieval spiritual culture the poem (psalms, taghs and gandzs) has a much greater role. It had and has the most of the role of religious function. It has not only the function of conveying but also communicating. In the first case, the spiritual poem appears as a literary-artistic unit, but in the second, it appears as a ritual unit. If the literaryartistic perception indicates the lower level of the poem than the religious one is its upper level" (Kyoseyan, 1995, pp. 168-169).

If the purpose of the ritual side is to convey the spiritual meaning, and its analysis is the monopole of the theology, then the primary method of word-image timber ensuring the communication is the spiritual symbol, the analysis of its content is impossible without applying the comparative method of philosophy, theology and the history of literature. Such approach will enable to uncover not only the main content of the spiritual symbol but also the entirety of the content of the spiritual-ideological structure of the artistic idea, which is the chief purpose of the composition in terms of ritual function.

The meaningful occurrence of the symbol and its lexical formation is a result of a longlasting process since the uncovering of the "sacred mystery" is not a particular vocabulary ex- planation of the hidden meanings. Especially at the initial stage "The world of Jesus is filled merely with "alien" and "new", "possible" and "impossible", "unheard" and "unseen", "strange" and "ineffable" things..." (Avernitsev, 1977, p. 144), which should reach the deeply meaningful and explained expression through the deep procedures of occurring and getting meaningful, i.e. to the level of cultural identity and uniqueness (literature, fine arts, music, architecture, etc.).

Thus, the symbolic-allegorical system of expressing the spiritual meanings of the scriptural speech virtually becomes the meaningful foundation for the expression of the symbolism of art and the prerequisite for its establishment. For the formation and development of the spiritual symbol of medieval art and later the history of theoretical thoughts about it undeniably confirms the conviction of Yu. Lotman (2000) that, "... even if we do not know what is the symbol, each system knows what is "its symbol" and needs it for the work of meaningful structure" (p. 240). This realisation of the system endows those mentioned above "impossible", "ineffable" things with new meanings and content, which, by presenting the allegorical portrayal of the very subject or phenomenon, they become "alien" from their initial, naming meanings and rise (or transform) to a level of multi-layer and polysemy expression that is the symbol. As the symbol is not a conditional sign, in the same way, it is not a method of discovering the allegorical world, that “...is not simple conventionality with the medieval perception, it is endowed with enormous significance and is filled with the deepest meaning. It is not a separate action or subject that is symbolic, isn't it? The whole world of this side is nothing but the symbol of the world of the other side: thus, every subject is endowed with a double and multiple meanings, and along with the 
practical application, it also has symbolic application. The world is a book written by God, in which every person represents a word that is full of meaning" (Guvrichev, 1972, p. 248).

\section{Conclusion}

Based on the statements as mentioned above, the following conclusions can be made:

1. The Armenian theorists of the Middle Ages while touching upon the description or definition of the symbol directly deprive it of the word meaning.

2. The symbol is probably the most reliable unit and criterion for the evaluation of the spiritual culture since the latter, with its inward-content and appearance - linguistic features are very constant and conservative. Never ever any world outlook or methodological approach can reinterpret or modify it, because as Yu. Lotman (2000) notes, "the memory of the symbol is always much older than its textual non-symbolic memory" (p. 240).

3. While defining the symbol, it is a must to accept as an imperishable precondition, the statement, that according to the thinking of the Middle Ages, the world of this side serves the invisible - the recognition of the world of the other side.

4. From the perspectives of Armenian medieval theorists, the following definition of the symbol can be drawn: through the visible, the people composing the world of this side, the concepts expressing the things and their relationships, the words and expressions that made the timber of the symbolic-allegoric speech uncovering the primary sacraments of the world of the other side - the invisible - are called spir itual symbols.

\section{REFERENCES}

Abeghyan, M. (1968). Erker (Selections, in Armenian) (Vol. III). Yerevan: Publishing House of the Armenian SSR.

Alvrtsyan, H. (2017). Hogevor taghi khorhrdabanut 'yuny' (Symbolism of the Spiritual Poem, in Armenian). Antelias Publishing House.

Avernitsev, S. (1977). Poetika rannevizantiiskoi literatury (Poetics of the Early Byzantine Literature, in Russian). Moscow: Nauka Publishers.

Bichkov, V. (1981). Estetika pozdnei antichnosti (Aesthetics of Late Antiquity, in Russian). Moscow: Nauka Publishers.

Confession of Vahram Rabuni. Matenadaran after Mesrop Mashtots, manuscript № 2678.

David the Invincible, (1980). Erkasirut'yunk pilisopayakank (Philosophical Work, in Armenian). Yerevan: Publishing House of the Armenian SSR.

Ghazaryan, V. (Ed.). (2004). Meknut'yunq khoranats, hetazotut'yun \& bnagrer (Interpretation of Canon-tables: Research and Originals). Mother See of Holy Etchmiadzin.

Ghulikyan, T. (2011). Yearbook: Vahram Rabunu Davanabanakan Hajatsqnery' (The Doctrinal Views of Vahram Rabuni, in Armenian). Yerevan: Zangak 97.

Tatevatsi, G. (2005). Erg Ergotsi Meknut'yun (Commentary of the Song of Songs, in Armenian). Yerevan: Ankyunaqar.

Guryevich, A. (1972). Kategorii srednevekovoi kul'tury (Categories of the Culture of 
the Middle Ages, in Russia). Moscow: Iskusstvo.

Odznetsi, Hovhannes Imastaser. (1953). Matenagrut'yunk (Bibliography, in Armenian). $2^{\text {nd }}$ ed. Venice: Surb Ghazar.

Khachatryan, P. (1996). Grigor Narekatsin \& hay mijnadary (Gregory Narekatsi and the Armenian Middle Ages, in Armenain). Echmiadzin: St. Echmiadzin Publishing House.

Kyoseyan, H. (1995). Drvagner mijnadaryan arvesti astvatsabanutyan (Episodes from the Theology of the Medieval art, in Armenian). Echmiadzin: St. Echmiadzin Publishing House.

Likhachev, D. (1985). Svoeobrazie istoricheskogo puti russkoi literatury X-XVII vv., $v$ sbornike Proshloe-budushchemu, Stat'i $i$ ocherki (The Peculiarity of the Historical Path of the Russian Literature in the X-XVII centuries: In the collection of the Past to the Future: Articles and Essays, in Russian). Leningrad: Nauka Publishers.

Lotman, Yu. (2000). Semiosphera (Semiosphere, in Russian). Saint Petersburg: Iskusstvo.

Narekatsi, G. (1840). Matenagrut'yunk (Bibliog raphy, in Armenian). Venice: Surb Ghazar.

Lambronatsi, N. (2004). Meknut'yun Soghomon imastuni (Commentary of Solomon, in Armenian). Yerevan: Erevani Hamalsarani Hratarakchutyun.

Nerses the Graceful. (1830). Banq chapav (Poetic Speech, in Armenian).Venice: Surb Ghazar.

Tamrazyan, Hr. (2004). Gregor Narekatsin \& norplatonakanut'yuny (Gregory Narekatsi and the New Platonism, in Armenian). Yerevan: Nairi.

The Holy Bible. (2014). King James Version. USA: Createspace Independent Publication.

Vetsorya (Six days). Matenadaran after Mesrop Mashtots, manuscript № 2229.

Yeghishe. (1859). Srbo horn mero Yeghishe vardapeti matenagrutyunk (Bibliography by Our Holy Father Yeghishe Archimandrite, in Armenian). Venice: Surb Ghazar.

Zaqaryan, S. (1997). Hay imastasernery (The Armenian Philosophers, in Armenian). Yerevan: Erevani Hamalsarani Hratarakchutyun. 